\title{
Antibacterial mechanism of Kratom (Mitragyna speciosa) methanol extract on Streptococcus pneumoniae and Eschericia coli bacteria
}

\author{
Hotimah Masdan Salim ${ }^{*(\mathbb{B})}$, Marinda Dwi Puspitarini', Yuani Setiwati ${ }^{(\mathbb{D})}$, Michio \\ Shimabukuro ${ }^{4}$
}

${ }^{1}$ Department of Biochesmitry medicine and Biomolecular science, Faculty of Medicine, Universitas Nahdlatul Ulama Surabaya, Indonesia

${ }^{2}$ Department of Microbiology, Faculty of Medicine, Universitas Nahdlatul Ulama Surabaya, Indonesia

${ }^{3}$ Division of Pharmacology and Therapy, Department of Anatomy, Histology and Pharmacology, Faculty of Medicine, Universitas Airlangga, Surabaya, Indonesia

${ }^{4}$ Department of Diabetes, Endocrinology and Metabolism.Fukushima Medical University, Japan

\section{A R T I C L E I N F O}

\section{Article history:}

Received 24 August 2021

Received in revised form 22

September 2019

Accepted 19 October 2021

Available online 30 June 2021

Keywords:

Mitragyna speciosa,

Streptococcus pneumoniae,

Eschericia coli,

insilico,

ATP1.

*) Corresponding author:

dr.hotimah@unusa.ac.id

\begin{abstract}
A B S T R A C T
Introduction: Kratom (Mitragyna speciosa) is a tropical herbal plant native to the North Malay Peninsula, Malaysia and Thailand. In Indonesia, kratom us a typical plant of West Kalimantan, especially in Putussibau. Kratom leaf has many pharmacological effects, one of them is antioxidant. However, the antioxidant and antimicrobial activities of Mitragyna speciosa leaf extracts are lacking. This study was to examine the effect of the methanol extract of Mitragyna speciosa (Rubiaceae Family) leaves on microorganisms Escherichia coli and Strepococcus pneumoniae.

Methods: Kratom leaves were extracted with methanol as solvent. In this study, S. pneumoniae and $E$. coli bacteria have been used. Antibacterial activity tests were carried out at concentrations of $0.78 \%, 1.56 \%, 3.125 \%, 6.25 \%, 12.5 \%, 25 \%, 50 \%$ and $100 \%$. Insilico was used to search for secondary metabolites and metabolite interactions in Mytragina speciosa.

Results: Mitragyna speciosa leaf methanol extract was effective in inhibiting the growth of $E$. coli and $S$. pneumoniae significantly $(\mathrm{P}<0.001)$. The growth of e.coli was not identified from a concentration of $25 \%$ to $100 \%$. However, there was no bacterial growth in $S$. pneumoniae from a concentration of $6.25 \%$ to $100 \%$. In the insilico study it was found that the secondary metabolite of Mitragyna speciosa is quercetin, which interacts with the ATP1 protein as a predictor in the mechanism of Mitragyna speciosa as an antibacterial.

Conclusion: In conclusion, there is no correlation between nutritional status and remission outcome of patients with ALL in the induction phase of therapy. However, high percentage of underweight patients shows nutrition needs special attention to improve therapy outcomes.
\end{abstract}

\begin{abstract}
Introduction
Indonesia has a lot of forests which are very wide with a variety of types of plants. Diversity of plant species in Indonesia, not much is known about its optimal use as a medicinal plant. ${ }^{1}$ Medicinal plants have species diversity to thousands of species. Where it is known that there are about 40,000 species of medicinal plants that have been known in the world, and 30.000 of them are suspected to be located in Indonesia. This number represents $90 \%$ of the plant drugs found in Asia. Of these, $25 \%$ of them or about 7.500 species are known to have herbal properties or medical plants. However, only 1.200 types of plants
\end{abstract}

have been used for raw materials for herbal medicines or herbs. ${ }^{2}$ One of the herbal plants is Kratom which is an herbal plant native to North Malay Peninsula, Malaysia, Thailand and Indonesia. ${ }^{3}$ In Indonesia, kratom is a plant that grows in West Kalimantan, especially in Putussibau district, which kratom leaves are known as "purik" leaves. In general, people consume kratom leaves by chewing, brewing like tea or smoking. ${ }^{4}$

Kratom is one of the traditional medicinal plants that produces stimulant (at low doses) and sedative effects (at high doses), diarrhea, smoothing blood circulation, increase endurance and stamina, prevent constipation, 
treatment for diabetes and reduce sugar levels. ${ }^{5}$ Previous studies on kratom leaves shows pharmacological effect activity, among those; analgesic and stimulants, antidepressant, anti-inflammatory and antinociceptive, antioxidant and antibacterial. ${ }^{6}$ The effectiveness of kratom as an antibacterial has been carried out on several types of bacterial, including the bacterial that cause acne namely Propionibacterium acnes, in Salmonella typhi and Bacillus subtilis.?

The activity of kratom as an antimicrobial cannot be separated from the composition contained in the kratom leaves, including the high content of phenolics and flavonoids in the methanol extract of kratom leaves. ${ }^{8}$

Phytochemical studies have shown that there are several chemical constituents of Mitragyna speciosa plants including indole alkaloids, including mitragynine, 7-hydroxymitraginine, 5-desmethylmitragynine, 17-desmethyldihydro-mitragynine, speciogynine, speciocilliatine, and paynantheine, ${ }^{9}$ and also contain secondary metabolites such as flavonoids, saponin, monoterpenes, triterpenoids, secoirioids and polyphenolic compounds. ${ }^{10}$

The antimicrobial potential of kratom is also expected to have an effect on the bacteria that cause respiratory and digestive tract infections. Therefore, this study aimed to examine the effect of kratom leaf as an antimicrobial on Staphylococcal pneumonia and E. coli bacteria.

\section{Methods}

\section{Plant material}

The plant of leaves of Mitragyna speciosa were collected from Putussibau state, West Kalimnatan, Indonesia. Mitragyna speciosa leaves are washed with water to remove dirt before the drying process. Then the leaves are cut and dried in direct sunlight for 2-3 days. After cutting the leaves and grounded into powder.

\section{Methanolic Extract}

The dried leaves of M. speciosa were ground in powder form. A total of $2.08 \mathrm{~kg}$ of Mitragyna speciosa powder was extracted using $96 \%$ methanol as solvent. The solvent was changed every $1 \times 24$ hours and macerated for $7 \times 24$ hours. After maceration, it was concentrated using a rotary evaporator and a water bath to obtain a thick extract of $20 \mathrm{~g}$ of crude methanol extract and stored at $-20^{\circ} \mathrm{C}$

\section{Test microorganisms and growth media}

We collected $S$. pneumoniae and $E$. coli provided by the Surabaya Health Laboratory Center (BBLK). Bacterial colonies were taken by means of inoculum suspension for 24 hours of culture, then suspended in sterile $0.9 \%$ $\mathrm{NaCL}$ solution.

\section{Antibacterial testing}

The antibacterial activity of Mitragyna speciosa leaf extract was tested by agar diffusion method using NA media. Bacterial suspension of $0.02 \mathrm{ml} \mathrm{1:40} \mathrm{dilution} \mathrm{was}$ mixed with $10 \mathrm{ml}$ of NA medium in a diluent bottle, then shaken unti 1 homogeneous. Take the inoculant in the tube and scratch it on a petri dish, and incubate at $37^{\circ} \mathrm{C}$ for 18-24 hours, then observe the growth of bacteria. Testing the antibacterial activity of kratom leaf extract against $S$. pneumoniae and $E$. coli as carried out with 8 (eight) variations of concentration namely $0.78 \%$, $1.56 \%, 3.72 \%, 6.25 \%, 12.5 \%, 25 \%, 50 \%$ and $100 \%$. The whole test tube incubated in an incubator at $37^{\circ} \mathrm{C}$ for 18-24 hours. Then make observations of the whole tube against tube clarity by viewing control.

\section{Insilico}

Screening of metabolite secondary of Mitragyna speciosa was carried out from http://www.swissadme.ch/index. php. The 3D structure of the active ingredient, a search was carried out from the PubChem (http://pubchem. ncbi.nlm.nih.gov) server with the recorded CID. Then to find out the interaction of secondary metabolites with proteins in the body, a search was carried out on the STITCH (http://stitch.embl.de) database server.

\section{Statistical analysis}

This research was repeated three times. All results are expressed as mean \pm SEM. Differences between groups were analyzed by one-way analysis of variance (ANOVA), followed by Tukey's post hoc analysis. Dose-response curve comparisons were made with a two-factor repeated-measurement ANOVA, followed by Tukey's post hoc test for comparison between groups. $\mathrm{P}<0.05$ was considered significant. analysis using SPSS version 21 program.

\section{Results}

Minimum Inhibitory Concentration of Methanol Extract of Mytragina Speciosa of E.Coli

Minimum Inhibitory Concentration of extract ethanol Mytragina Speciosa of E. coli showed that the activity decreased at a concentration of $25 \%, 50 \%$ and $100 \%$ (figure.1A), where there was no visible bacterial growth compared to the control group. The bacterial count also showed that the lower the extract concentration, the more bacterial growth (Figure.1B)

Figure.1 Antimicroba activity (MIC) of Mytragyna speciosa extract in E. coli

\section{Minimum Inhibitory Concentration of Methanol Extract of Mytragina Speciosa in Strepococcus pneumoniae}

Minimum Inhibitory Concentration of Extract Methanol Mitragyna Speciosa of $S$. pneumoniae showed that the activity decreased at a concentration of $6,25 \% 12,5 \%$, $25 \%, 50 \%$ and $100 \%$ (figure. $2 \mathrm{~A}$ ), where there was no visible bacterial growth compared to the control group. The bacterial count also showed that the lower the extract concentration, the more bacterial growth (Figure.2B) Figure.2 Antimicroba activity (MIC) of Mytragyna speciosa extract in Strep.penumonia

\section{Interaction of kratom secondary metabolite compounds}

Based on previous research, the composition of the methanol extract of Mytragina speciosa has been obtained. In this study we examine the interaction of the active compound from the methanolic extract of mitragyna speciosa, namely quercetin which is the equivalent of the flavonoid content. (Figure.3) 
(A)

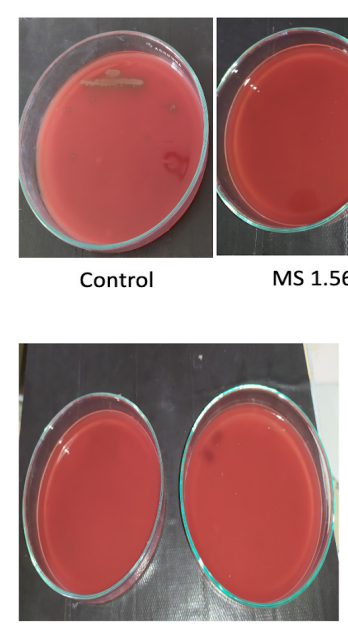

MS $25 \% \quad$ MS $12.5 \%$

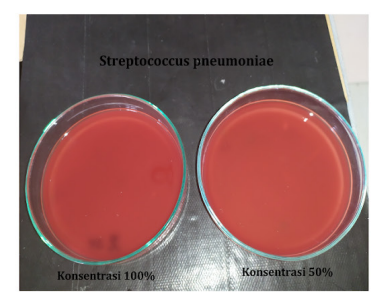

MS $100 \% \quad$ MS $50 \%$
(B)

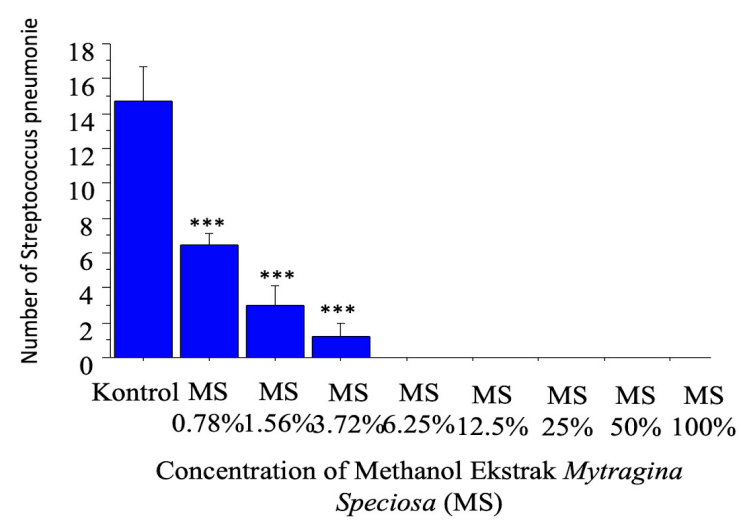

Figure 1. Minimum Inhibitor Concentration of Methanol Extract of Mytragina Speciosa in E.Coli. Ctrl; Control, MS; Mitragyna Speciosa. ${ }^{* *} ; \mathrm{P}<0.01,{ }^{* * *} ; \mathrm{P}<0.001$ vs control group

(A)

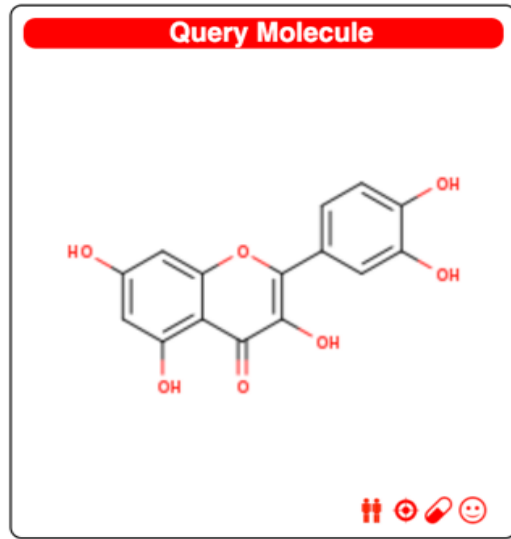

(B)

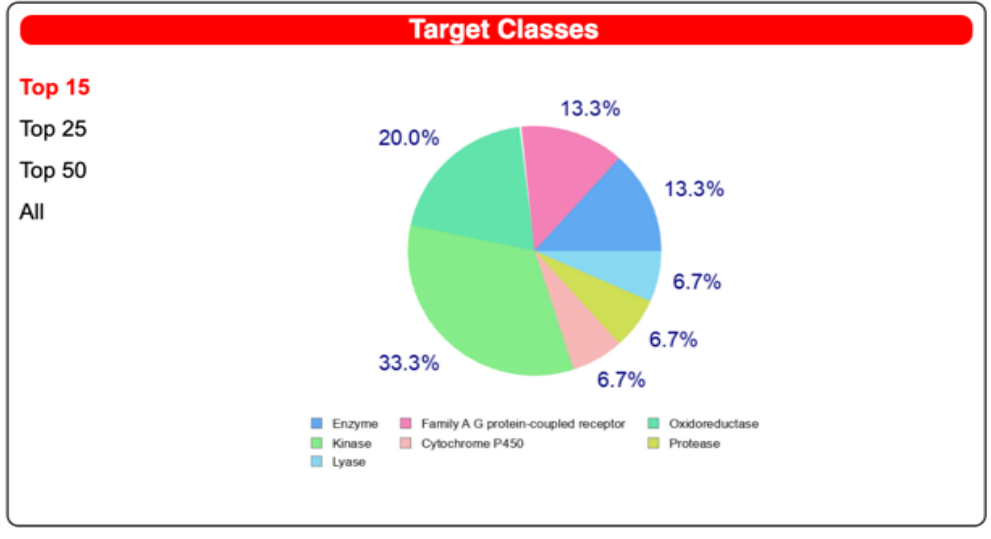

Figure L. Ivınımum inniditory Concentration or vietnanol Extract or Mytragına speciosa in streptococcus penumonie. Ctrl; Control, MS; Mitragyna Speciosa. **; $\mathrm{P}<0.01,{ }^{* * * ;} ; \mathrm{P}<0.001$ vs control group

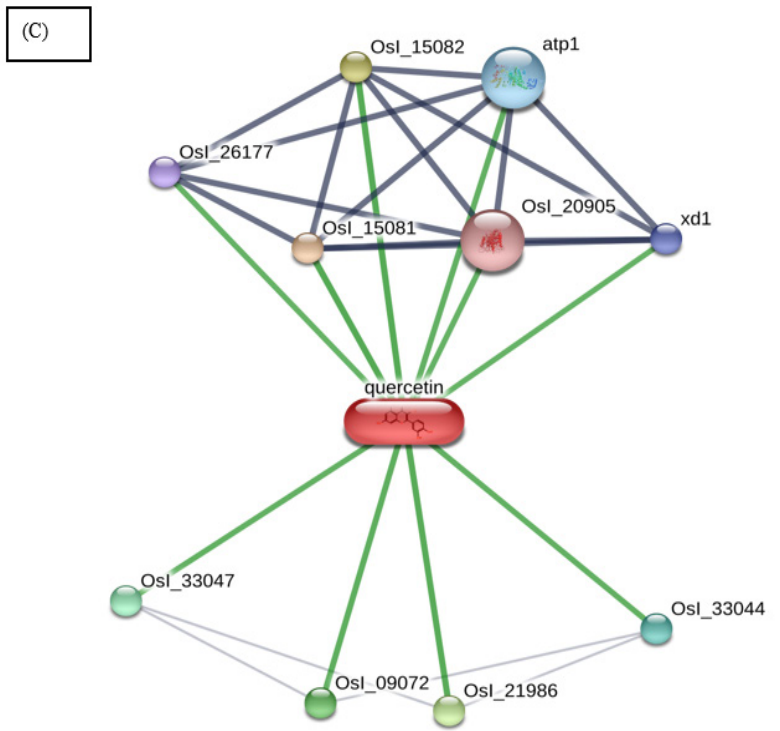

Figure. 3 prediction of interactions between chemicals (quercetin) and proteins in the body insilico. 
Quercetine is a flavonoid that is widely found in plants. In this insilico quercetine has an interaction bond with atp1. ATP synthase $(\mathrm{F}(1) \mathrm{F}(0)$ ATP synthase or Complex $\mathrm{V})$ generates ATP from ADP in the presence of a proton gradient across the membrane generated by the electron transport complex of the respiratory chain. This quercetin interaction is predictive of its antimicrobial activity by inhibiting ATP1 synthesis at the cellular level. While osl and $\mathrm{xd} 1$ are proteins that do not have special characteristics.

\section{Discussion}

In this study, it was found that the methanolic extract of Mitragyna speciosa (Kratom) had an antimicrobial effect on bacteria that cause respiratory tract infection and bacteria in the digestive tract. The results of this study showed that Mytragina speciosa methanol extract was effective as an antimicrobial at higher concentrations. Where in this study found at a concentration of more than $12.5 \%$ Escherichia coli bacteria were not found, and at concentrations $>3.72 \%$ Streptococcus pneumoniae bacteria. In line with this study, previous studies have shown the effectiveness of Mytragina speciosa as an antimicrobial of several types of extract solvents. Antimicrobial activity was found to be effective in $\mathrm{MeoH}$ and Alkaloid extracts, which have the ability to inhibit growth and kill larger bacteria Salmonella typhi and Bacillus subtilis. ${ }^{8}$ Other studies have also found that kratom has an antimicrobial effect that has an inhibitory effect on Aeromonas hydrophylla. ${ }^{7}$

Antibacterial activity test shows that increasing the concentration of extract given can increase the killing power of the extract against bacteria. However, if the concentration of the extract continues to increase, it can reduce the killing power. This finding suggested that the increasing concentration of Kratom can lead to an increase in viscosity of the extract, thus affecting the rate of diffusion of extract in agar media. In addition to the concentration factor, the type of antimicrobial material can also determine the ability to inhibit bacterial growth. ${ }^{11}$

The effectiveness of kratom as an antimicrobial has been known for a long time, based on the results of phytochemicals in kratom leaves, it has been found that kratom leaves contain alkaloid, flavonoids, steroid, saponin and tannins and have antioxidant effect. ${ }^{12}$ It has been found in previous studies that compounds derived from plants have antibacterial activity based on phytochemical data. The components of the active substances in mitragyna speciosa extract have been proven, including alkaloids, flavonoids, saponin, tannins, phenols and other active compounds. ${ }^{13}$

In nature, flavonoid compounds are products extracted from plants and they are found in several parts of the plant. Flavonoids play a variety of biological activities in plants, animals and bacteria. Flavonoids are associated with a wide spectrum of health-promoting effects and are indispensable components in a wide range of nutraceutical, pharmaceutical, medicinal and cosmetic applications. This is due to its antioxidant, anti-inflammatory, antimutagenic and anti-carcinogenic properties coupled with its capacity to modulate the function of key cellular enzymes. ${ }^{14}$ In previous studies, it was found that the active substance of the flavonoid class is quercetin in methanol extract of Mitragyna speciosa..$^{15}$

The quercetin content in the $\mathrm{MeOH}$ Kratom extract is quite high. The presence of quercetin as a sub-flavonoid gives hope that the content of kratom has a good effect for use as herbal medicine. In this study we found that quercetin has a high pharmacokinetic effect on absorption in the gastrointestinal tract. In addition, to find out of mechanism target of quercetin, we examine in insilico studies. this study showed predictions of quercetine's target of action on enzymes, oxidoreductase, G-protein receptors, enzymes, proteases, lyase and cytochrome $\mathrm{p} 450$. Based on the results of this study, it is possible that the quercetin content in the Methanol kratom extract has the ability as an antibacterial against Streptococcus pneumoniae and Eschericia coli. This tudy is supported by the results of previous studies which found that quercetin inhibits the formation of streptococcus pneumoniae biofilms. ${ }^{16}$

In addition, other studies also found that quercetine in surgacane bagasse extract showed bacteriostatic activity against the growth of $S$. aureus, L. monocytogenes, E. coli, and $S$. typhimurium, ${ }^{17}$ and could change ATP activity, thus effecting the growth of E.coli. ${ }^{18}$ In an in vivo study, it was found that quercetin can protect mice from s.aureus infection by inhibiting thrombin activity. ${ }^{19}$ To confirm the interaction of quercetine with proteins in the body, we performed an insilico screening. In this study it was found that quercetine can interact with ATP synthase FO subunit 1 (ATP1) in humans. As we know that ATP is the main energy compound in biological synthesis, and most of it is provided by the F1FO-ATP synthase which is located in the membrane and can be found in bacteria, mitochondria and chloroplasts. ${ }^{20}$

The findings in this study can be used as a basis for explaining the mechanism that methanol extract of Mitragina speciosa (kratom) leaves has an antibacterial effect on Streptococcus pneumoniae and Eschericial coli, through the mechanism of inhibition of ATP synthase Fo subunit 1 (ATP1).

\section{Conclusion}

Mytragina speciosa (kratom) methanol extract has an antimicrobial effect on streptococcus pneumonia and e.coli through the effect of quercetine contained in kratom. This antimicrobial mechanism is thought to be by inhibiting ATP synthesis through the ATP synthase F0 subunit 1 (atp1) pathway. The broad spectrum antimicrobial properties of quercetin can be used in the prevention and treatment of various infectious bacterial diseases and may provide a treatment option to reduce the use of antibiotics.

\section{Acknowledgement}

We would like to thanks LPPM Universitas Nahdlatul Ulama Surabaya for providing financial support and to Miss Gardina as staff in the microbiology laboratory for guiding us in the laboratory.

\section{Conflict of Interest}

The author stated there is no conflict of interest 


\section{References}

1. Wiryono, Puteri, V. N. U. \& Senoaji, G. The diversity of plant species, the types of plant uses and the estimate of carbon stock in agroforestry system in Harapan Makmur Village, Bengkulu, Indonesia. Biodiversitas 17, 249-255 (2016).

2. PT Industri Jamu Dan Farmasi Sido Muncul Tbk. Inspiring for a Better Life. (2019).

3. Hassan, R. et al. Mitragynine Attenuates Morphine Withdrawal Effects in Rats-A Comparison With Methadone and Buprenorphine. Front. psychiatry 11, 411 (2020).

4. Henningfield, J. E., Fant, R. V \& Wang, D. W. The abuse potential of kratom according the 8 factors of the controlled substances act: implications for regulation and research. Psychopharmacology (Berl). 235, 573-589 (2018).

5. Fluyau, D. \& Revadigar, N. Biochemical Benefits, Diagnosis, and Clinical Risks Evaluation of Kratom. Front. psychiatry 8, 62 (2017).

6. Cheaha, D. et al. Effects of alkaloid-rich extract from Mitragyna speciosa (Korth.) Havil. on naloxone-precipitated morphine withdrawal symptoms and local field potential in the nucleus accumbens of mice. J. Ethnopharmacol. 208, 129-137 (2017).

7. Juanda, E., Andayani, S. \& Maftuch, M. Phytochemical Screening and Antibacterial Activity of Kratom Leaf (Mitragyna speciosa Korth.) Against Aeromonas hydrophilla. J. Exp. Life Sci. 9, 155158 (2019).

8. Parthasarathy, S. et al. Evaluation of antioxidant and antibacterial activities of aqueous, methanolic and alkaloid extracts from Mitragyna speciosa (Rubiaceae family) leaves. Molecules 14, 3964-3974 (2009).

9. Basiliere, S., Bryand, K. \& Kerrigan, S. Identification of five Mitragyna alkaloids in urine using liquid chromatographyquadrupole/time of flight mass spectrometry. J. Chromatogr. B 1080, 11-19 (2018).

10. Raffa, R. B. Kratom and other mitragynines: the chemistry and pharmacology of opioids from a non-opium source. (CRC Press, 2014).
11. Li, J. et al. Antimicrobial Activity and Resistance: Influencing Factors. Front. Pharmacol. 8, 364 (2017).

12. Yuniarti, R. et al. Characterization, Phytochemical Screenings and Antioxidant Activity Test of Kratom Leaf Ethanol Extract (Mitragyna speciosa Korth) Using DPPH Method. J. Phys. Conf. Ser. 1462, (2020).

13. León, F. et al. Phytochemical Characterization of the Leaves of Mitragyna Speciosa Grown in USA. Nat. Prod. Commun. 4, 1934578X0900400705 (2009).

14. Khalid, M., Saeed-ur-Rahman, Bilal, M. \& HUANG, D. Role of flavonoids in plant interactions with the environment and against human pathogens - A review. J. Integr. Agric. 18, 211-230 (2019).

15. Pandey, B. P., Pradhan, S. P. \& Adhikari, K. LC_ESi_QTOF_MS for the Profiling of the Metabolites and in Vitro Enzymes Inhibition Activity of Bryophyllum pinnatum and Oxalis corniculata Collected from Ramechhap District of Nepal. Chem. I\& Biodivers. 17, (2020).

16. Wang, J. et al. Quercetin increzases the antioxidant capacity of the ovary in menopausal rats and in ovarian granulosa cell culture in vitro. J. Ovarian Res. 11, 51 (2018).

17. Zhao, Y., Chen, M., Zhao, Z. \& Yu, S. The antibiotic activity and mechanisms of sugarcane (Saccharum officinarum L.) bagasse extract against food-borne pathogens. Food Chem. 185, 112-118 (2015).

18. Yang, D., Wang, T., Long, M. \& Li, P. Quercetin: Its Main Pharmacological Activity and Potential Application in Clinical Medicine. Oxid. Med. Cell. Longev. 2020, 8825387 (2020).

19. Wang, L. et al. Quercetin protects rats from catheter-related Staphylococcus aureus infections by inhibiting coagulase activity. J. Cell. Mol. Med. 23, 4808-4818 (2019).

20. Walker, J. E. The ATP synthase: the understood, the uncertain and the unknown. Biochem. Soc. Trans. 41, 1-16 (2013). 